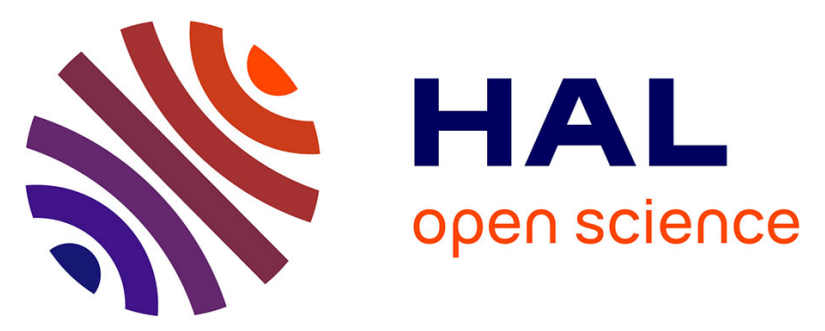

\title{
European Association of Cardiothoracic Anesthesiology and Intensive Care Pediatric Cardiac Anesthesia Fellowship Curriculum: First Edition
}

Mohamed El-Tahan, Gabor Erdoes, Joost van Der Maaten, Kirstin Wilkinson, Theofili Kousi, Theofani Antoniou, Vera von Dossow, Caetano Nigro Neto, Ehrenfried Schindler, Andrea Székely, et al.

\section{To cite this version:}

Mohamed El-Tahan, Gabor Erdoes, Joost van Der Maaten, Kirstin Wilkinson, Theofili Kousi, et al.. European Association of Cardiothoracic Anesthesiology and Intensive Care Pediatric Cardiac Anesthesia Fellowship Curriculum: First Edition. Journal of Cardiothoracic and Vascular Anesthesia, 2021, 10.1053/j.jvca.2021.08.009 . hal-03377792

\section{HAL Id: hal-03377792 \\ https://hal.science/hal-03377792}

Submitted on 14 Oct 2021

HAL is a multi-disciplinary open access archive for the deposit and dissemination of scientific research documents, whether they are published or not. The documents may come from teaching and research institutions in France or abroad, or from public or private research centers.
L'archive ouverte pluridisciplinaire HAL, est destinée au dépôt et à la diffusion de documents scientifiques de niveau recherche, publiés ou non, émanant des établissements d'enseignement et de recherche français ou étrangers, des laboratoires publics ou privés. 


\title{
European Association of Cardiothoracic Anesthesiology and Intensive Care Pediatric Cardiac Anesthesia Fellowship Curriculum: First Edition
}

\author{
Mohamed R. El-Tahan, MD* , Gabor Erdoes, $\mathrm{MD}, \mathrm{PhD}^{\dagger}$, \\ Joost van der Maaten, $\mathrm{MD}^{\ddagger}$, Kirstin Wilkinson, MB, BS, FRCA ${ }^{\S}$, \\ Theofili Kousi, MD, $\mathrm{PhD}^{\top}$, Theofani Antoniou, $\mathrm{MD}, \mathrm{PhD}^{\top}$, \\ Vera von Dossow, $\mathrm{MD}^{\#}$, Caetano Nigro Neto, MD, PhD", \\ Ehrenfried Schindler, MD, $\mathrm{PhD}^{* *}$, Andrea Székely, MD, $\mathrm{PhD}^{\dagger \dagger}$, \\ Anna Flo Forner, $\mathrm{MD}^{\ddagger \ddagger}$, Patrick F. Wouters, $\mathrm{MD}, \mathrm{PhD}^{\S}$,

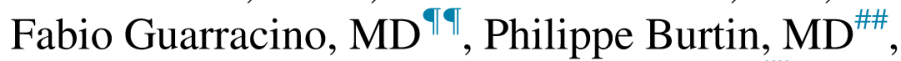 \\ Dragana Unic-Stojanovic, $\mathrm{MD}, \mathrm{PhD}^{\mathrm{III}}$, \\ Jan-Uwe Schreiber, MD, PhD***, Purificación Matute, $\mathrm{MD}, \mathrm{PhD}^{\dagger \dagger \dagger}$ \\ , Fawzia Aboulfetouh, MD ${ }^{\dagger \dagger}$, Ricard Navarro-Ripoll, MD ${ }^{\dagger \dagger \dagger}$, \\ Jens Fassl, MD, $\operatorname{PhD}^{\S \S \S}$, Dominique Bettex, MD ${ }^{\text {बबा }}$,

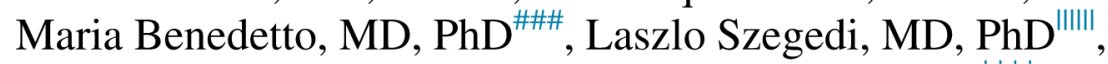 \\ R. Peter Alston, MD****, Giovanni Landoni, $\mathrm{MD}^{\dagger \dagger}$, \\ Manuel Granell, MD, PhD ${ }^{+\ddagger}$, Philippe Gaudard, $\mathrm{MD}, \mathrm{PhD}^{\S \S \S \S}$, \\ Sascha Treskatsch, MD, PhD ${ }^{\text {बाब }}$, Dieter Van Beersel, MD ${ }^{\# \# \#, ~}$ \\ Alain Vuylsteke, $\mathrm{MD}^{\||\|||| \mid}$, Simon Howell, MD******, \\ Aniruddha R. Janai, MD ${ }^{+\star}$ \\ Alberto Hernandez Martinez, MD, PhD ${ }^{\dagger \dagger \dagger \dagger}$, \\ Joachim M. Erb, MD ${ }^{\ddagger \dagger}$, Marc Vives, MD ${ }^{\S \S \S \S \S, ~}$ \\ Hossam El-Ashmawi, MD ${ }^{\text {बाबा }}$, Steffen Rex, MD, PhD \#\#\#, \\ Chirojit Mukherjee, MD, PhD ${ }^{\# \# \# \# \text {, Gianluca Paternoster, MD }}{ }^{\prime \prime|||||| !, ~}$ \\ Mona Momeni, MD, $\mathrm{PhD} * * * * * *,{ }^{\mathrm{a}}$

\footnotetext{
*Cardiothoracic Anesthesia, Anesthesia, Surgical Intensive Care and Pain Medicine, College of Medicine, Mansoura University, Mansoura, Egypt. Imam Abdulrahman Bin Faisal University, Dammam, Saudi Arabia ${ }^{\dagger}$ Department of Anesthesiology and Pain Medicine, Inselspital, Bern University Hospital, University of Bern, Bern, Switzerland

${ }^{\ddagger}$ Department of Anesthesiology, University Medical Center Groningen, Groningen, The Netherlands ${ }^{\S}$ Cardiac Anaesthesia and Critical Care, University Hospital Southampton, Tremona Road, Southampton, United Kingdom
} \\ Onassis Cardiac Surgery Center, Athens, Greece
}

${ }^{\mathrm{a}}$ Address correspondence to Mona Momeni, MD, PhD, Department of Anesthesiology, Cliniques Universitaires Saint Luc, Université Catholique de Louvain, Institut de Recherche Expérimentale et Clinique, Brussels, Belgium

E-mail address: mona.momeni@uclouvain.be (M. Momeni). 


\footnotetext{
${ }^{\#}$ Institute of Anesthesiology, German Heart and Diabetes Center Bad Oeynhausen, Ruhr-University Bochum, Bad Oeynhausen, Germany

"Dante Pazzanese Institute of Cardiology, São Paulo, Brazil

** Department of Anesthesiology and Intensive Care Medicine, University Hospital Bonn, Bonn, Germany

${ }^{\dagger}$ Professor of Anesthesia, Department of Anesthesia, Semmelweis University, Budapest, Hungary

${ }^{\mathrm{\dagger}}$ Department of Anesthesiology, Heart Center Leipzig, University of Leipzig, Leipzig, German

${ }^{\S}$ University Department of Fundamental and Applied Medical Sciences and Clinical Department of Anesthesiology and Perioperative Medicine, Ghent, Belgium

${ }^{\top}$ Department of Anesthesia and Critical Care Medicine, Azienda Ospedaliero-Universitaria Pisana, Pisa, Italy

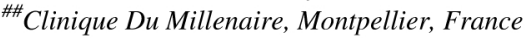

IIIIInstitute for Cardiovascular Diseases Dedinje, School of Medicine University of Belgrade, Belgrade, Serbia

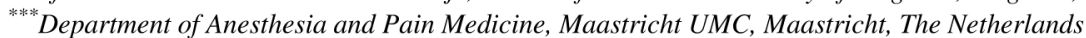

${ }^{\dagger \dagger}$ Department of Anesthesia and Intensive Care, Hospital Clinic Barcelona, Spain

${ }^{\sharp \dagger}$ Department of Anesthesiology, Cairo University, Vice-Rector of Academic and Research Affairs, Misr University for Science and Technology (MUST), Cairo, Egypt

${ }^{\dagger \dagger}$ Department of Anesthesia and Intensive Care, Hospital Clinic Barcelona, Spain

${ }^{\S \S \S}$ Department of Cardiac Anesthesiology, Heart Center of the Technical University of Dresden, Dresden, Germany

${ }^{\top \top \uparrow}$ Institute of Anesthesiology, University and University Hospital Zurich, Zurich, Switzerland

\#\#\#Paediatric and Adult cardiothoracic and vascular department of Anaesthesia and Intensive care, Sant' Orsola University Hospital, Bologna, Italy

IIIII'Department of Anesthesiology, Hopital Erasme, Brussels, Belgium

***** Department of Anaesthesia, Critical Care and Pain Medicine, Royal Infirmary of Edinburgh, Edinburgh, United Kingdom

${ }^{\dagger+\dagger \dagger}$ Anesthesia and Intensive Care Department, IRCCS San Raffaele Scientific Institute, Milan, Italy, VitaSalute San Raffaele University, Milan, Italy

${ }^{\$}$ Professor Anesthesiology and Intensive Care, University of Valencia. Spain. Department of Anesthesia, Critical Care and Pain Medicine, University General Hospital Consortium of Valencia, Valencia, Spain

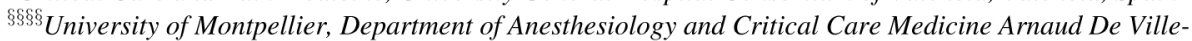
neuve, CHU Montpellier, PhyMedExp, INSERM, CNRS, Montpellier, France

१๑ศ Department of Anesthesiology, Charité Campus Benjamin Franklin, Berlin, Germany

\#\#\# Department of Anesthesiology, University Hospitals Leuven, Leuven, Belgium

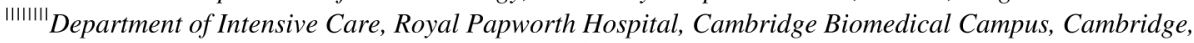
United Kingdom

*****:Leeds Institute of Biomedical and Clinical Sciences, University of Leeds, St. James's University Hospital, Leeds, United Kingdom

${ }^{\dagger \dagger}{ }^{\dagger}$ Department of Anesthesia and Intensive Care, Hospital Universitari Bellvitge, Barcelona, Grupo Policlinica, Ibiza, Spain

$+\vdots+\ddagger \ddagger$ Clinic for Anaesthesiology, Intermediate Care, Prehospital Emergency Medicine and Pain Therapy, University Hospital Basel, Basel, Switzerland

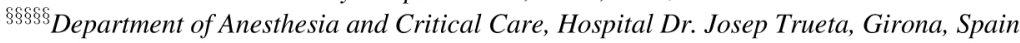

๑ศ ฯฯ Professor of Anesthesiology, Surgical Intensive care Unit, and Pain Management, Faculty of Medicine, Cairo University, Cairo, Egypt

\#\#\#\# Department of Anesthesia \& Intensive Care, Helios Clinic for Cardiac Surgery, Karlsruhe, Germany

${ }^{\prime \prime I I ! ! !}$ Division of Cardiac Resuscitation, Cardiovascular Anesthesia and Intensive Care, San Carlo Hospital, Potenza, Italy

Department of Anesthesiology, Cliniques Universitaires Saint Luc, Université Catholique de Louvain, Institut de Recherche Expérimentale et Clinique, Brussels, Belgium
}

\begin{abstract}
Pediatric cardiac anesthesia is a subspecialty of cardiac and pediatric anesthesiology dedicated to the perioperative care of patients with congenital heart disease. Members of the Congenital and Education Subcommittees of the European Association of Cardiothoracic Anaesthesiology and Intensive Care (EACTAIC) agreed on the necessity to develop an EACTAIC pediatric cardiac anesthesia fellowship curriculum. This manuscript represents a consensus on the composition and the design of the EACTAIC Pediatric Cardiac Anesthesia Fellowship program. This curriculum provides a basis for the training of future pediatric cardiac anesthesiologists by clearly defining the theoretical and practical requirements for fellows and host centers.
\end{abstract}

(C) 2021 Elsevier Inc. All rights reserved.

PEDIATRIC CARDIAC ANESTHESIA is a subspecialty of cardiac and pediatric anesthesiology dedicated to the perioperative care of patients with congenital heart disease (CHD). The care of patients with CHD ranges in age from the neonatal period to adulthood. Fellowship programs for pediatric cardiac anesthesia are established in the United States but not accredited by the Accreditation Council for Graduate Medical Education (ACGME). ${ }^{1,2}$ No comparable fellowship program is currently available in Europe. Over the last few years, members of the Education and Congenital Subcommittees of the 
European Association of Cardiothoracic Anaesthesiology and Intensive Care (EACTAIC) increasingly have recognized the necessity to establish a European Pediatric Cardiac Anesthesia (PCA) Fellowship Program. For this reason, they chose to formulate a PCA program curriculum with the aim of educating anesthesiologists to follow a defined training program that will improve their knowledge and skills in the perioperative care of patients with CHD.

\section{Methods}

EACTAIC's Board of Directors approved the development of a standardized curriculum for the EACTAIC Fellowship Programs in cardiothoracic and vascular anesthesia, including PCA, on October 02, 2017. In September 2019 and November 2020, members of the EACTAIC Pediatric and Congenital Subspecialty Committees held two meetings to discuss the feasibility of developing an advanced training module or a separate fellowship program in PCA.

On November 17, 2020, the members of the EACTAIC Educational Committee established a task force, including 12 members experienced in PCA from both pediatric and congenital subspecialty and education committees, to draft a curriculum for a PCA Fellowship Program. The project's overall scope was determined through a search and review of the available literature on PCA published until December 11, 2020.

The members of the task force actively involved in the first draft of the EACTAIC PCA Fellowship followed the regulations of EACTAIC for the curriculum of adult cardiothoracic and vascular anesthesia, ${ }^{3}$ the white paper of the board of directors, ${ }^{4}$ the tasks required by the EACTAIC hosting centers, ${ }^{5}$ and other EACTAIC regulatory policies for the fellowship programs. ${ }^{6,7}$ The study authors also considered the PCA proposal submitted by the Task Force for Standardization of the Pediatric Cardiac Anesthesiology Fellowship to the ACGME. ${ }^{1,2,8}$

Two internet-based surveys regarding the PCA Fellowship Program were performed. Recipients of the questionnaires, along with written information about the aims and objectives of the survey, data handling, and management, were current members of the EACTAIC Education Committees and Task Force. The questionnaires were uploaded to the Survey Monkey platform, and the survey links were distributed by email to all members of the EACTAIC Education Committee and Task Force. Reminders were emailed until the end of the stated collection periods.

The first questionnaire was distributed to the 30 members in December 2020 by sending two email invitations.

The questionnaire included the following questions: the minimum duration of training in the EACTAIC PCA Fellowship, the minimum required number of cardiac surgical cases per year during the PCA Fellowship, and the required prior experience in pediatric general anesthesia and/or cardiac anesthesia.

Using a modified Delphi process to generate an agreement among the 35 current members, the second survey was undertaken in May 2021, followed by sending an email invitation and seven reminders. The survey was composed of two parts, including a 137-item questionnaire on the proposed knowledge, technical and nontechnical skills, the 'obligatory' rotation through a pediatric intensive care unit (PICU), and the minimum caseloads for the different types of cardiac surgery and interventional procedures required to be performed. The first part of the survey included a screening of the acceptability of respondents, using a traffic light system to evaluate whether this proposed knowledge, technical and nontechnical skills, 'obligatory' rotation in a PICU, and types of surgical and interventional procedures performed should be included in the final curriculum. The traffic light system was defined as green indicating need and yellow as useful to be included, whereas red signified that the subject was not important enough to be included. The respondents were instructed to choose only one traffic light color for each suggested solution. Successful suggestions required at least two-thirds of the respondents, giving green or yellow ratings, to be considered a consensus in the EACTAIC Education Committee and Task Force.

The second part of the questionnaire included a quantitative survey with responses on an ordinal five-point Likert scale defined as a score of 1-to-5 corresponding to 'strongly agree,' 'agree,' 'neither agree nor disagree,' 'disagree,' and 'strongly disagree.' The agreement was defined as achieved when $>70 \%$ of experts strongly agreed or agreed to a given option on the Likert scale for a statement. ${ }^{9}$

All participants provided consent for participation, and data analysis and participation were voluntary and anonymous. All collected data were anonymized, secured, and will remain confidential in the EACTAIC archiving system for ten years following the general data protection regulations (accessible at https://eugdpr.org/).

The final results of these surveys and the expert clinical practice statements were circulated among the experts in the task force. A draft manuscript then was distributed to all of the experts in the EACTAIC Education Committee and Board of Directors for editing and approval before it was submitted for publication.

\section{Statistical Analysis}

Data management and descriptive statistics (number, percentages, median, and interquartile range) were performed using the IBM SPSS Statistics Subscription, Base Edition (Statistical Package for Statistical Analysis, IBM Ireland Product Distribution Limited, IBM House, Shelburne Road, Ballsbridge, Dublin 4, Ireland).

\section{Results}

The initial survey period was set from December 7 to December 14, 2020. Upon closure of the survey, 27 responses were received ( $90 \%$ response rate). All respondents completed the questionnaire. The majority of respondents chose one-year (82\%) and 100 cases (70\%) as the minimum duration of training and number of cardiac surgical patients performed per year 


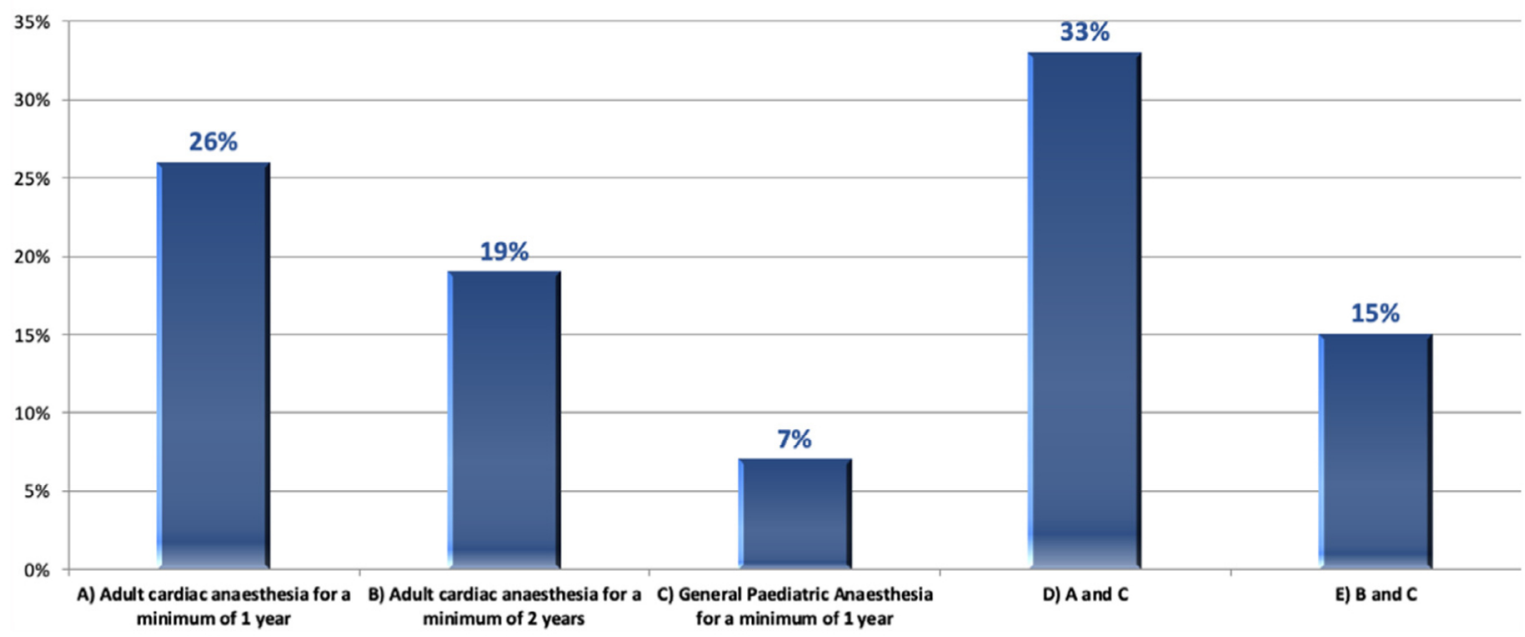

Fig. 1. The choices on the duration of the previous experience in pediatric anesthesia and adult cardiac anesthesia.

that would be required during the EACTAIC PCA fellowship training. A minority of respondents chose six-month (4\%) or two-year periods $(18 \%)$. One-third of the respondents reported that the applicant to the EACTAIC PCA program should be required to have had a minimum of one year's prior experience in both adult cardiothoracic and vascular anesthesia and pediatric anesthesia to enroll in the EACTAIC PCA Fellowship Program. All responses indicated by respondents are reported in Figure 1.

The second survey was undertaken from May 1 to May 10, 2021. Two members within the Education Committee declined to participate because they had very limited experience in pediatric anesthesia. Upon closure of the survey, a total of 30 responses were received from the 33 members of the EACTAIC Education Committee and Task Force (response rate of 91\%). Twenty-seven respondents provided responses to all questions in the questionnaire.

More than $90 \%$ of the 30 respondents indicated green or yellow traffic lights to rate the importance of including knowledge, technical and nontechnical skills, an obligatory rotation through PICU, and types of cardiac surgery and interventional procedures in the final version of the curriculum. As only $82 \%$ of respondents chose green or yellow traffic lights to rate the importance of including the minimum exposure to 20 cases with extracorporeal life support (ECLS) over the year in the curriculum (Supplement A), these 20 cases were excluded from the suggested number of cases in Table 1.

At the end of the second round of the survey, 40 of the 41 statements $(98 \%)$ had achieved agreement from the proposed Union Européenne des Médecins Spécialistes levels for knowledge, technical and nontechnical skills, and 'obligatory' rotations in a pediatric intensive care unit (PICU) and interventional pediatric cardiology. Agreement was achieved in 15 of the 23 statements $(65 \%)$ on the proposed 'optional' numbers of surgical and interventional procedures performed during the fellowship training year (Supplement B). The nine

statements, including the types of cases that failed to reach consensus, were excluded from Table 1.

Table 1

Minimum Recommended Number of Cases for Anesthetic Management of Cardiac Surgery and Interventional Procedures in Patients With CHD $^{1,2, *, \dagger}$

\section{Surgical Cases With CPB}

Ventricular and/or atrial septal defect

Atrioventricular septal defect

Tetralogy of Fallot

Left-sided valvular lesions

Bidirectional Glenn

Fontan procedure

Miscellaneous including Rastelli and

Damus-Kaye-Stansel procedures,

intracardiac tumors

\section{Surgical cases without CPB}

Modified Blalock-Taussig shunts

Coarctation repair

Pulmonary artery banding

PDA closure

Treatment of vascular rings

Cardiac percutaneous intervention

procedures

Diagnostic

Neonatal aortic and/or pulmonary vessel or valve treatment (eg, pulmonary artery stenosis,

coarctation)

ASD/VSD/PDA device closure

Other therapeutic

Electrophysiology studies

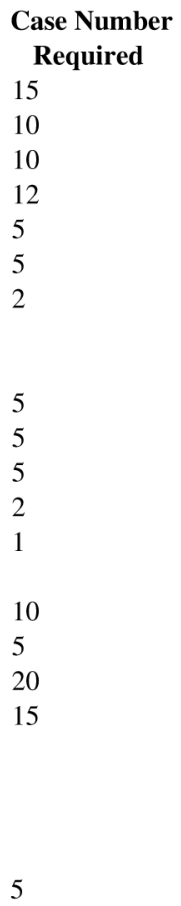

Abbreviations: ASD, atrial septal defect; CHD, congenital heart disease; CPB, cardiopulmonary bypass; PDA, patent ductus arteriosus; VSD, ventricular septal defect.

* These recommended numbers of cases are not obligatory and depend mainly on where the fellowship program takes place. However, as stated in the text, a minimum of 100 surgical cases and a minimum of 50 pediatric cardiac interventional procedures need to be performed per calendar year.

$\dagger$ The types of cases that failed to reach consensus were excluded. 


\section{Limitations of the Surveys}

These surveys had some limitations. First, many respondents to the surveys were not involved in European societies' programs interested in pediatric cardiac anesthesia training. However, some members of the Task Force are involved in the Congenital Cardiac Anaesthesia Network in the United Kingdom and the European Society for Paediatric Anaesthesiology. Second, there seemed to be a considerable adult bias to the survey, as many respondents practice adult and pediatric cardiac anesthesia. However, this does not mean minimizing the experience in pediatric anesthesia and pediatric intensive care. This PCA program instead will help standardize this curriculum and emphasize the importance of the pediatric aspect.

\section{Curriculum Design and Certification}

The PCA Fellowship Program will be open to all physicians irrespective of their country of origin, religion, gender, or sexual orientation. ${ }^{3}$ Before being accepted as a fellow, candidates must provide evidence of their valid license to practice medicine and a specialist qualification in anesthesiology at their national level. Furthermore, candidates must provide evidence of their prior fellowship training or work experience in (1) adult cardiac anesthesia for a minimum of one year and (2) general pediatric anesthesia for a minimum of one year at a nationally or internationally recognized center with the dedicated care for this patient population. Preferably, this training may have taken place within the framework of a fellowship; for example, adult cardiovascular and thoracic fellowship program of EACTAIC. ${ }^{3}$ That is not similar to the United States' centers, which require prior completion of a pediatric anesthesia fellowship or an adult cardiothoracic anesthesia fellowship to join the dedicated second-year fellowship training in PCA. ${ }^{1}$

Candidates are required to be members in good standing of EACTAIC. A letter of recommendation from two established members of EACTAIC specializing in cardiac and/or pediatric anesthesia should be submitted together with the application for the PCA program. The candidate's supporters vouch for the candidate's successful completion of prior training and suitability to train as a pediatric cardiac anesthesiologist. Applicants must present proof of appropriate language skills as defined by the host centers and required in accordance with national and international regulations (generally level B2). ${ }^{3}$

The PCA program's total duration is 12 months, including a one-month rotation through the PICU. The center hosting the fellowship program must undertake a minimum of 100 pediatric cardiac surgery cases and 50 pediatric cardiac interventional procedures per calendar year. The majority of surgical cases should be performed using extracorporeal circulation. ${ }^{2}$ The cardiac interventional experience needs to be considered important, as it is an evolving part of managing patients with CHD. Ideally, $50 \%$ of cases should be performed in children aged younger than four years and $20 \%$ in children aged younger than one month. Patients will be considered pediatric as long as their age is 16 years or younger. ${ }^{1,2}$ Simultaneous management of adults with congenital heart disease is encouraged and should be considered in the center's PCA certification process whenever possible.

Ideally, EACTAIC accredits one center to stand alone to host the PCA Fellowship Program if it has enough cases. EACTAIC favorably considers the accreditation of two or more centers collaborating together to stand as a single host center that offers the full EACTAIC PCA Fellowship Program with a three-to-six -month exchange fellowship training rotations between them. Prior agreement regarding the duration of the rotation and the number of cases to be performed should be achieved between these centers. All of the following regulations will apply to each of the collaborating centers so as to support the fellow achieving the required minimum number of cases performed per year and the levels of competencies. When only a few or limited varieties of pediatric cardiac cases are performed in a host center, a compound exchange-training plan involving more than one center should be discussed with all parties involved (eg, Fellow PCA Program Director) before the PCA fellowship is initiated. The chair of the EACTAIC Education Committee must approve in advance an appropriate exchange-training plan.

The training period will be completed under the close supervision of a mentor who is also the local PCA Program Director or the responsible consultant for pediatric cardiac anesthesia. Mentors who are the program director and faculty members involved in the training program should all be members of EACTAIC in good standing. ${ }^{3}$ The mentor must provide the fellow with one-on-one clinical supervision during the first six months of the training and based on the conditional independence on a case-by-case assessment by the mentor. Fellows may manage simple cases with supervision from elsewhere in the hospital, but complex cases must have direct supervision. According to educational attainment, the mentor's supervision of the fellow should become more indirect. The mentor should nevertheless be physically present in the hospital and promptly available within a short duration.

The PCA Fellowship Program should be completed uninterrupted by frequent and/or prolonged periods of absence because of illness or personal circumstances. Absence from training for sick leave or personal circumstances requires a proportionate extension of the training period. Annual and maternity leave are regulated following local contractual requirements, provided that the knowledge, skills, and competency levels and the required number of cases are completed. Should it prove impossible to complete the required number of cases, the fellowship training period should be extended so that they can be completed. Appeals for exceptional circumstances because of illness or personal circumstances that have resulted in repeated or prolonged interruption of training will be reviewed by the Chair of the EACTAIC Education Committee, who will forward it to delegated members for arbitration. $^{3}$

EACTAIC undertakes indirect measures for the quality assurance on completion of Fellowship Programs, (1) including the collection of feedback from all graduates; (2) a graduate survey to facilitate the search for suitable postgraduate job opportunities; (3) reaccreditation of host centers every four 
years to ensure the maintenance of the required educational level; and (4) forwarding collected feedback arising from the final exit interviews to the program directors for self-improvement of host centers. ${ }^{3}$ To be noted, EACTAIC does not receive any fees for auditing programs and certification of individuals. The applying center for hosting the EACTAIC PCA Fellowship Program will cover the travel costs and the hotel accommodations of the two inspectors evaluating the host center during the one-day site visit. ${ }^{4}$

\section{Competencies for a PCA Fellowship Program}

The PCA Fellowship Program's competencies and milestones are based on a combination of medical knowledge, technical and nontechnical skills, and a didactic teaching program. For each domain, learning objectives are deemed necessary to achieve the required level of competence as defined by the Union Européenne des Médecins Spécialistes ${ }^{10,11}$ :

A: observer level (has knowledge of, describes)

B: performs, manages, and demonstrates under direct supervision

$\mathrm{C}$ : performs, manages, and demonstrates under distant supervision

D: performs, manages, and demonstrates independently

To ensure that all content and skills can be adequately learned during the PCA Fellowship, EACTAIC recommends a minimum number of procedures/patients treated per domain, as outlined in Table 1 . The candidate is required to have met these minimum requirements before applying for the final assessment. The recommended numbers of different types of cases in Table 1 are not obligatory and depend mainly on where the fellowship program occurs.

\section{Medical knowledge [Level A]}

Cardiac and Extracardiac Anatomy and Related Factors

- Knowledge of congenital cardiac anatomy and morphology, as well as congenital and acquired cardiac lesions.

- Knowledge of congenital anomalies, associated syndromes, and extracardiac comorbidities.

- Knowledge of the pathophysiology of congenital cardiac lesions.

- Knowledge and understanding of cardiovascular surgical and catheter-based therapeutic procedures.

- Knowledge of pathophysiology associated with surgical and catheter-based diagnostic and therapeutic procedures

- Understanding the decision-making steps for surgical and catheter-based interventional procedures from the neonatal period to adulthood.

- To be aware of potential complications associated with the placement of arterial and venous catheters. To have knowledge of the specific material [Level A]

- Knowledge of transesophageal echocardiography (TEE) imaging in CHD and the complications related to the TEE probe insertion. [Level A]
- Knowledge of the basic principles of ultrasound and Doppler technology [Level A] and the uses of ultrasound imaging for facilitating vascular access. [Level A]

Principles of Cardiopulmonary Bypass (CPB) and

Extracorporeal Life Support (ECLS) [Level A]

- Knowledge of basic principles of cardiopulmonary bypass (CPB) and ECLS.

- Knowledge of adverse events related to CPB and ECLS.

- Knowledge of myocardial protection during cardiac surgery.

- Knowledge of noncardiac organ protection.

- Knowledge of hypothermic circulatory arrest and cerebral perfusion strategies.

- Knowledge of circuit priming strategies for CPB.

- Knowledge of the actions of different cardioplegic solutions and their benefits and drawbacks.

- Knowledge of coagulopathies related to CPB and their prophylaxis and treatment.

- Knowledge of hemodynamic and pharmacokinetic management during CPB.

\section{Pharmacology of Pediatric Cardiac Anesthesia [Level A]}

- Knowledge of pharmacologic principles and action of anesthetic agents in pediatric patients with CHD.

- Knowledge of pharmacologic principles of positive inotropic, vasoactive, anti-arrhythmic, and pulmonary vasodilator drugs.

- Preparation of a safe anesthetic plan, including adequate perioperative analgesia, taking into account the hemodynamic status of the patient and the expected postoperative recovery.

\section{Cardiac Imaging}

- To interpret echocardiographic images, it is recommended to follow the EACTAIC (or European Society of Cardiology) echocardiography course on CHD or any local affordable pediatric echocardiography course. [Level C]

- Understanding cardiac catheterization images. [Level C]

- Knowledge of intraoperative TEE related to CHD and the recognition of complications. [Level A]

- Basic understanding of other cardiac imaging modalities, including magnetic resonance imaging and computed tomography. [Level A]

Anesthesia for Cardiovascular Surgical and Catheter-Based Interventional Procedures

- Preanesthetic assessment (obtaining medical and surgical history including any associated syndromes (eg, Trisomy 21, DiGeorge, Williams, etc.) or comorbidities, the performance of physical examination, and obtaining informed consent). [Level D]

- Optimizes preparation of CHD patients, including medical therapy and need for further investigation. [Level D] 
- Interprets data from preoperative cardiothoracic diagnostic imaging. [Level C]

- Identifies and anticipates hemodynamic, medical, and surgical issues in the pre- and post-CPB periods in the function of the predicted risk estimation as defined by Risk Adjustment for Congenital Heart Surgery (RACHS-1). [Level D]

- Identifies and anticipates hemodynamic, medical, and surgical issues in patients undergoing palliative surgery without CPB. [Level D]

- Applies and correctly interprets necessary invasive hemodynamic and noninvasive neurologic monitoring and TEE. [Level D]

- Applies safe perioperative patient blood management and is aware of transfusion-related complications. [Level D]

- Applies safe anesthesia for diagnostic and interventional heart catheterizations in patients ranging in age from neonates to adults. [Level C]

- Applies safe anesthesia for electrophysiological procedures in children and adults. [Level C]

- Has knowledge of the type and the duration of the most important operations and related anesthetic management. [Level D]

- Applies safe transport of patients to the PICU. [Level D]

\section{Technical Skills ${ }^{1,2}$}

- Recognizes unique characteristics of pediatric cardiac anatomy, airway management, and vascular access. [Level D]

- Anticipates difficult airway management in patients with specific syndromes and uses specific equipment, and demonstrates competency in managing the difficult airways in neonates, children, and adults. [Level D]

- Demonstrates competency in the placement of peripheral and central venous lines and arterial catheters with and without ultrasound imaging. [Level D]

- Passing the theoretical part of an adult TEE certification course as, for example, the European Association of Cardiovascular Imaging-EACTAIC or any other recognized national or international certification, is mandatory to complete the PCA fellowship program. The completion of the electronic case book is recommended. [Level C]

- Use of TEE for diagnosis and management of various cases. [Level C]

- Is familiar with point-of-care coagulation testing and can guide transfusion based on their results. [Level D]

- Is familiar with the use of cerebral and somatic near-infrared spectroscopy. [Level D]

- Applies regional analgesia and lung-isolation techniques when required. [Level D]

\section{Didactic Program and Nontechnical Skills}

- Fellows must participate in journal clubs, multidisciplinary discussions, and morbidity and mortality meetings organized within the host center. [Level D]
- Fellows must participate in online webinars and annual scientific meetings to obtain five- to-ten continuing medical education credits and participation in EACTAIC's Annual Congress is highly recommended.

- Fellows must undertake self-directed learning and scholarly activity by reviewing literature related to a case or a specific patient-related topic. [Level D]

- Whenever possible, the fellow actively participates in research projects or the development of guidelines or policies. [Level B]

- Fellows must present, at least once per year, case reports or research projects at departmental educational, national, and international meetings. [Level D]

- Fellows must develop:

- communication skills with patients and parents [Level D]

- communication of appropriate information to families and patients in the pre- and postoperative periods [Level D]

- the ability to communicate with families from different cultural and/or religious backgrounds [Level D]

- skills to communicate adverse information about patient complications, or medical errors [Level D]

- Fellows seek to establish effective collaboration with other team members within and outside the department. Fellows accept feedback and incorporate it into their practice to improve their skills. [Level D]

- Fellows develop effective communication skills with members of other departments including surgeons, cardiologists, intensive care physicians, and nurses. [Level D]

- Fellows strictly follow Patient Safety Guidelines. [Level D]

\section{Assessment}

General Principles of Assessment

The faculty members responsible for teaching fellows will provide the PCA Program Director with critical evaluations of each fellow's progress and competence at four-month intervals using a standardized format. The evaluations will assess essential and acquired character attributes, level of knowledge, clinical judgment, psychomotor skills, and specific procedural skills needed for patient management and critical analysis of clinical situations. ${ }^{3}$

The PCA Program Director or a designate will provide feedback to fellows on their evaluations at least every four months during their training, identifying areas in need of improvement, and will document the communication in writing. Fellows must obtain a satisfactory overall evaluation on completion of their training to receive certification. ${ }^{3}$ A portfolio containing a logbook of all cases undertaken by fellows is required for each assessment period (see template).

\section{Assessment of Fellows}

The following elements will form part of the assessment of the fellow during their training. In addition to evaluation by faculty members and the EACTAIC Representative(s), it will 
Table 2

Assessment Tools ${ }^{3}$

- Evaluation discussions through the fellowship program every four months.

- During discussions with Fellows, the tutor or Head of Training will address the following:

$\square$ Results of 360-degree evaluations ${ }^{*}$ and clinical skills evaluations.

$\square$ Personal reports from the faculty (if available).

$\square$ Reflections and self-assessments by the Fellow.

$\square$ Learning goals for the next four months.

$\square$ Feedback from Fellows on the quality of the education and any aspects of the curriculum that has not been addressed in their training.

* A 360-degree evaluation (of CanMEDS competencies): 360-degree feedback is a diagnostic tool that helps the candidate to improve his/her personal competencies and supports the self-assessment. During the fellowship, a minimum of one 360-degree feedback must include at least 5 colleagues invited to submit an evaluation of the candidate's competencies. Feedback is restricted to internal sources (supervising anesthesiologists, surgeons, nurses) using a standardized questionnaire based on existing multi-source feedback forms. ${ }^{11,12}$

$\dagger$ Clinical skills evaluation (CSE) or Direct Observation of Procedural Skills: Clinical skills evaluation (CSE) is intended to give feedback to the Fellow about his ability to plan and perform various clinical tasks. CSE is to be performed by a supervisor, the head of training, or another appropriate person (cardiothoracic anesthesiologist with experience in CHD) based on a standardized form, which can be based on already existing forms. ${ }^{13}$

be essential for the fellow to learn from reflection on their training experiences. ${ }^{3}$ Assessment tools are listed in Table 2.

\section{Documentation}

Fellows are required to complete a record of their training during their fellowship in the form of a logbook. If available, an electronic system, such as a computer database, may be used. The following information should be documented in the logbook:

- Anonymized record of all patients managed by fellows during their fellowship. The data set recorded for each case must include a minimum of age, weight, sex, RACHS-1, type of surgery or percutaneous intervention procedure, anesthetic procedure(s), relevant comorbidities, and the performed techniques.

- If applicable, reports of TEE examinations.

- Summaries of their four-month evaluations and related discussions.

- Results of their clinical skills evaluations. ${ }^{13}$

- 360-degree multisource feedback. ${ }^{11}$

\section{External Evaluation and/or Assessment}

At the end of the fellowship, and with the exception of the 360-degree multisource feedback, all of the contents of the logbook must be sent to the Chair of the Education Committee. ${ }^{3}$ The chair then will forward it to two representatives of EACTAIC, who are not associated with the host center, for assessment. ${ }^{3}$ Also, fellows must undergo an exit interview by an advisory committee formed by two external examiners and the program director alone from the host center (Supplement C). ${ }^{6}$ Fellows can apply for the interview once they have completed the required number of procedures, internships outside the operating room, CSE, and 360-degree evaluation. The external evaluation or assessment is scored as pass or fail and yes or no (360-degree evaluation). An average score of $70 \%$ or above is required to pass (Supplement D). ${ }^{3}$ The advisory committee should provide feedback to the fellow, describing both the documentary evidence's strengths and weaknesses. Fellows will be awarded certification if they obtain a 'pass' mark on CSE and complete all other assessment tools (eg, 360-degree evaluation). ${ }^{3}$ If this is not the case, the training will be deemed incomplete, and the fellow will not be awarded certification in the EACTAIC Fellowship Program. ${ }^{3}$ These fellows will have to be enrolled for an additional period of training at the host center under either direct or remote supervision until showing the competency, knowledge and skills levels required based on the conditional independence on a case-by-case assessment by the mentor in order to satisfactorily fulfill the requirements. ${ }^{3}$ Fellows who feel they were unfairly denied certification may appeal the decision of the advisory committee within seven working days after the interview. ${ }^{3}$ The appeal must be submitted in the form of a signed and dated letter to the chair of the education committee and sent by registered mail within the expiration period. The advisory committee's decision regarding the appeal will be communicated to fellows within $20 \mathrm{cal}-$ endar days after the appeal was received (Supplement E). ${ }^{7}$

\section{Program Assessment}

There will be regular opportunities for fellows to provide confidential written evaluations of the faculty and program to the Chair of the EACTAIC Education Committee. ${ }^{14}$

Fellows who experience difficulty during their training period may turn for advice to the program director, faculty members, and the head of the department at the host center. Fellows who feel unable to approach any of these people should contact the Chair of the EACTAIC Education Committee. The chair can provide confidential, neutral, independent, and informal advice to help fellows address their concerns. ${ }^{3,14}$ The chair can support the fellow in person in any discussions of problems or issues with faculty or administrators, as well as act as an informal mediator between the trainee and the faculty or administrators. The chair also can help effect positive change by providing feedback on patterns in problems and complaints submitted to the program director. Fellows can contact the chair with general questions by email, telephone, or in person. A staged approach policy is available in escalating issues with noncompliant host centers for EACTAIC PCA fellowship programs (Supplement E). ${ }^{15}$

Periodic evaluation of patient care (quality assurance) is mandatory. ${ }^{3}$ Subspecialty trainees in adult cardiac (preferentially adults with CHD) and general pediatric anesthesia will be involved in continuing quality improvement and risk management.

Should unforeseen circumstances arise, such as a personal conflict between a fellow and one or more tutors, this should 
be reported immediately to the Chair of the Education Committee. The board of directors then has the right to appoint an independent EACTAIC officer as a "mentor" to help resolve the circumstances and protect both parties. ${ }^{3,4}$

\section{Conclusion}

EACTAIC initiated its Fellowship Program in PCA to ensure training is both of high quality and standardized. A consensus requires to be developed among centers hosting Fellowship Programs as to the knowledge, skills, and competence that are necessary to take care of children and adults with CHD. The EACTAIC Curriculum for PCA includes requirements for, and certification of, training, educational objectives, relevant competencies, and learning and teaching methods. Further assessments of the diverse practice among the European centers and the PCA Fellowship Program are essential to establish the efficacy of the proposed curriculum. The goal of EACTAIC's PCA Fellowship Program is to produce highly trained and competent perioperative physicians who can care for patients with CHD undergoing cardiac surgery and interventional procedures as well as noncardiac surgery.

\section{Supplementary Material}

Supplementary data associated with this article can be found in the online version at http://dx.doi.org/.

\section{Conflict of Interest}

None

\section{References}

1 Nasr VG, Guzzetta NA, Miller-Hance WC, et al. Consensus statement by the Congenital Cardiac Anesthesia Society: Milestones for the pediatric cardiac anesthesia fellowship. Anesth Analg 2018;126:198-207.

2 Nasr VG, Guzzetta NA, Mossad EB. Fellowship training in pediatric cardiac anesthesia: History, maturation, and current status. Cardiothorac Vasc Anesth 2019;33:1828-34.

3 Erdoes G, Vuylsteke A, Schreiber JU, et al. European Association of Cardiothoracic Anesthesiology (EACTA) cardiothoracic and vascular anesthesia fellowship curriculum: First edition. J Cardiothorac Vasc Anesth 2020;34:1132-41.

4 European Association of Cardiothoracic Anaesthesiology and Intensive Care. White paper of the board of directors for approving the hosting centres for the EACTAIC CTVA Fellowship Programme. Available at: https://www.eactaic.org/wp-content/uploads/2021/07/White-paper_upd25.06.21.pdf. Accessed July 17, 2021.

5 European Association of Cardiothoracic Anaesthesiology and Intensive Care. Tasks required by the hosting centres, Available at: https://www.eac taic.org/wp-content/uploads/PDF/tasks-required-by-the-host-centres_afterapproval_approved.pdf. Accessed June 6, 2021.

6 European Association of Cardiothoracic Anaesthesiology and Intensive Care. European Association of Cardiothoracic Anaesthesiology and Intensive Care (EACTAIC) sequence of procedures for EACTAIC Exit Interviews. Available at: https://www.eactaic.org/wp-content/uploads/PDF/ EACTA_Sequence_of_procedures_for_Exit_Interviews_Effective_26.11.2020.pdf. Accessed June 6, 2021.

7 European Association of Cardiothoracic Anaesthesiology and Intensive Care. The process for appealing the decisions of an examiner or their professional conduct during an exit interview from an EACTAIC Fellowship. Available at: https://www.eactaic.org/wp-content/uploads/2020/11/EACTA_Exit_Interview_Appeal_Process_Effective_26.11.2020.pdf. Accessed June 6, 2021.

8 Nasr VG, Andropoulos DB, Deutsch N, et al. Pediatric cardiac anesthesiology proposal for ACGME accreditation October 2020. Congenital Cardiac Anesthesia Society, The Task Force for Standardization of the Pediatric Cardiac Anesthesiology Fellowship. Available at: https://www.acgme.org/ Portals/0/PFAssets/ProposalReviewandComment/ACGMEProposalPediatricCardiacAnesthesiologyOctober2020.pdf. Accessed August 1, 2021.

9 Nasa P, Azoulay E, Khanna AK, et al. Expert consensus statements for the management of COVID-19-related acute respiratory failure using a Delphi method. Crit Care 2021;25:106.

10 European Board of Anaesthesiology. Union Européenne des Médecins Spécialistes (UEMS) Anaesthesiology Section. Training Requirements for the Specialty of Anaesthesiology. Pain and Intensive Care Medicine. European Standards of Postgraduate Medical Specialist Training. UEMS; 2021.2013/18. Available at: https://www.uems.eu/_data/assets/pdf_file/ 0004/44428/UEMS-2013.18-European-Training-Requirements-Anaesthesiology.pdfAccessed June 6.

11 Frank JR, Snell L, Sherbino J, (eds). CanMEDS 2015 Physician Competency Framework. Ottawa: Royal College of Physicians and Surgeons of Canada; 2015. Available at: http://canmeds.royalcollege.ca/uploads/en/ framework/CanMEDS\%202015\%20Framework_EN_Reduced.pdf. Accessed June 6, 2021.

12 Australian and New Zealand College of Anaesthetists (ANZCA). Multisource Feedback (MSF) Paper Form. Available at: https://www.anzca.edu. au/resources/forms/training-program-forms/anzca-training-programforms/wba-multi-source-feedback-(msf)-paper-formAccessed June 6.

13 Royal College of Anaesthetists. Direct observation of procedural skills [DOPS] assessment form. Available at: https://rcoa.ac.uk/sites/default/ files/documents/2019-12/DOPS_2016_v1.0.pdf. Accessed June 6, 2021.

14 El Tahan MR, Vasquez LEM, Alston RP, et al. Perspectives on the fellowship training in cardiac, thoracic, and vascular anesthesia and critical care in Europe from program directors and educational leads around Europe. J Cardiothorac Vasc Anesth 2020;34:512-20.

15 European Association of Cardiothoracic Anaesthesiology and Intensive Care. A staged approach policy for dealing with the noncompliant host centres for EACTA fellowship programs. Available at: https://www.eactaic.org/wp-content/uploads/2020/12/EACTA-Policy-for-Dealing-with-NoncompliantCentres_20.11.2020-SJH-comment.pdf. Accessed June 6, 2021. 